\title{
3D GEOMETRIC EXTRACTION USING SEGMENTATION FOR ASSET MANAGEMENT
}

\author{
Syameer Faiz Khir Anuar ${ }^{1}$, Amalin A’ishah Mohd Nasir ${ }^{1}$, Suhaibah Azri ${ }^{1}$, Uznir Ujang ${ }^{1}$, Zulkepli Majid ${ }^{1}$, Miguel González \\ Cuétara $^{2}$ and Guillermo De Miguel Retortillo ${ }^{2}$ \\ ${ }^{1}$ Department of Geoinformation, Faculty of Built Environment and Surveying, Universiti Teknologi Malaysia, 81310 Johor \\ Bahru, Malaysia \\ sfaiz2@live.utm.my, aaishah2@live.utm.my, Suhaibah@utm.my, mduznir@utm.my, zulkeplimajid@utm.my \\ ${ }^{2}$ Planta $5^{\text {a }}$ Oficina 16, Calle Luis Álvarez Lencero, 3, 06011 Badajoz, Spain \\ ceo@ecapture3d.com, guillermo@ecapture3d.com
}

Commission VI, WG VI/4

Keywords: Asset management, 3D model, Point Clouds, Segmentations, Smart City

\begin{abstract}
:
In recent years, there has been an increase in development of urbanization in the world. Nowadays, all communities in the world are concerned about current technological developments especially in terms of development and management that can facilitate their daily life. In urbanization, smart city is one of modernization changes that improves the infrastructure management, convenience and efficient for the life of citizens. Moreover, 3D asset management is one of the approach of smart city development. Asset management using the 3D concept has been witnessing a welcoming approach due to its high efficiency in organising multiple assets. 3D geometric extraction offers a perfect aid in recording information of an asset such as buildings. The model is derived from the reality techniques where the exterior surfaces of an object are captured in high resolution through the means of special equipment such as airborne imagery. From here, point clouds are generated where the sets of points based on the external surfaces of an object are present. Pre-processing of point clouds should be done in order to perform the 3D modelling. In dealing with point clouds, segmentations are used to investigate the structure of the object with information regarding to different level of sections. The boon behind this segmentation process is to identify different features that is available for the object. In this research, the aim is to analyse the different methodology and algorithm available to segment the point cloud data. Comparison between the results will be made to identify the advantages and disadvantages of the results for the use of asset management.
\end{abstract}

\section{INTRODUCTION}

The development of urbanization is a non-ending phenomenon in the world. For the next few decades, urbanization will have a rapid expansion because of the population growth. Moreover, because of the rapid expansion, the environmental, economy and social sustainability will also face changes. So, Smart city concept is one of the ways to improve quality of life and the management of urbanization. A smart city is a municipality that uses information and communication technologies (ICT) to increase operational efficiency, share information with public and improve both of the quality of government services and citizen welfare(Rouse, 2020). A smart city is a framework, predominantly composed of Information and Communication Technologies (ICT), to develop, deploy and promote sustainable development practices to address growing urbanization challenges (Thales, 2019).

Smart cities are developed and delivered across the five key segments, buildings and facilities, transportation systems, public services, resource management and infrastructure (HarborResearch, 2020). Asset management is one of the smart city approach. Asset management is a collection of information on the assets. Asset management is a system that has been used by the public and organizations to manage and maintain infrastructure and building assets. There are some challenges that lie towards the transition of asset management to a smart city (Chaturvedi, 2019). The major challenges that lie in smart city development are that the urban planning technique and outdated management. This will cause some delays in the city development. To build a smart city, available resources, skills in planning and development, coordination and collaboration are needed. A proper management of assets can guarantee the success and resourcefulness of the city.

The use of smart city technologies in urban design and planning requires a clear understanding of IT support solutions which should be providing adequate development platforms to the urban application domains (Volkov et al., 2018). Besides, the recent development of $3 \mathrm{D}$ technologies and tools have increased the availability and relevance of $3 \mathrm{D}$ data in the geospatial and geoinformation domain (Toschi et al., 2017). 3D data acquisition and modelling are one of the required method for the development of asset management for smart city development. Moreover, advanced analysis could be 
enhanced by using this modelling (see Azri et al., 2018; Azri et al., 2014). 3D data acquisition that involving operational sensor are such as laser scanning, radar, thermal, acoustic and others. This types of method are very popular because of their successful approach, faster and relatively cheap over the past few years. Moreover, $3 \mathrm{D}$ data modelling and visualization can be constructed from the 3D data acquisition. Thus, the production of 3D modeling and visualisation will give an impact towards asset management as a major contribution of smart city development.

In this paper, Point Cloud Segmentation will become one of the initial approach towards the smart cities development. The 'smart city' concept entirely relies on a permanent stream of massive amounts of data acquired by a great variety of sensors distributed throughout the city (Lemmens, 2018). The smart cities development requires data integration with 3D city map with the help of point cloud as the main sources. 3D geometric extraction using segmentation is a method that is integrated with the current technologies and ICT. Point cloud is not a new approach introduced to the current urban development but it is one of the contribution towards urbanization. 3D point cloud segmentation is the process of classifying point clouds into multiple homogeneous regions, the points in the same region will have the same properties (Nguyen, 2013). The segmentation of point cloud is the fundamental step in 3D point cloud processing. The point cloud segmentation is being used for automatic recognition of the building and their sub-elements. The 3D information of the building will be benefited for the segmentation. Moreover, the point cloud segmentation able to detect and recognize the geometric elements of the building. Thus, the point cloud segmentation approach could be one of the method used in the smart cities development for recognition of elements of the buildings.

\subsection{Overview on Asset Management}

Assets are known as a resource to any organisation that represents the economic value. It has been seen that something contributes into income generation for an organisation. The asset management has been seen as the process of the maintenance of assets. The importance of having an asset management is to enable one to keep tabs on the assets. The owner of the assets will know where and how the assets were used. Also, asset management helps to identify the risks posed by the assets itself. This is seen to be important so that mitigation of risks can be done.

The implementation of 3D data in Geographical Information System (GIS) can be seen in many (Salleh et al., 2018; Keling et al., 2017; Yusoff et al., 2011). Furthermore, the use of GIS in decision making do ease the process in making final verdict (Mohd et al., 2016). On the other hand, 3D GIS has made asset management to be more easily managed since the assets can be specified in the certain location (Makkonen, 2016). A streamlined output and reducing time cost make 3D GIS increasingly popular among various organisations. The advantage posed by 3D GIS is the efficiency in detection of specific features of the asset while the assessment of flaws posed by the asset can be made.
In regards to the immovable asset data, point clouds are the fundamental things that were needed to produce and analyse the assets. Point clouds were meant by the set of points that are extracted and scanned through the exterior of an object. The benefits of data acquisition from point clouds is that it allows the original features of the object to be retained and used for further analysis, making it perfect for $3 \mathrm{D}$ model segmentation processes.

Point cloud segmentation is an important first step in categorising a raw point cloud data (Murtiyoso, 2019). It is a necessary step for the managing of data and generating other derivative products. For the asset management, the point cloud segmentation can play an important role. As widely known, asset management is one of the smart cities concept that is applying 3D representation in its applications. In asset management application, point cloud will be used for data collection of the building structure, features and visualizing 3D models. With the point cloud segmentation, the assets and feature of the building can be identified easily. The high-fidelity of point cloud dataset that can be generated will be a significant method to many organizations as for increasing the accuracy of asset management systems.

\subsection{Immovable Assets}

Immovable assets can be defined as the piece of property that is fixed to the surface of the land. The definition behind this meaning is that the asset can only be moved when it is destroyed or altered. It is bound by the geographical location and the features can come in the form of building.

The problems raised include the long focus on 2D asset management. The objects can be viewed not in the full 3D view and this will lead to high error thus can be led to a poor documentation process (Innovation, 2007). Immovable assets such as building will have many different features. Analysis on the immovable assets can be a tiresome process where features cannot be identified properly due to numerous number of assets in the storage. Data redundancy can occur when using the traditional way in handling the immovable assets data which is why 3D asset management is in favour. Visualisation problems of the asset made it hard to be identified especially when it involves complex structure (Esri, 2014). This leads to the purpose of this research where segmentation method can be the way to overcome this problem. It is worth noting that the inaccuracies of $3 \mathrm{D}$ remodelling occurs due to the difficulties in differentiating the features in point clouds (Brous et al., 2015). From these problems, it is clear that the way to overcome this is by performing segmentation processes so that the features can be extracted and modelled for further analysis.

\subsection{Segmentation}

Segmentation is defined literally as the division of an object into separate parts. The objective of the 3D geometric segmentation can be traced to show the representation of parts of the object to make it manageable in the analysis process (Grilli et al., 2017). This is an important process where it helps to classify the different features posed by the immovable assets. In this research, 
two methods were analysed which are the region-growing method and scalar method. These two methods were assessed where the results determined which of these two methods are superior in analysing the immovable asset.

Region-growing segmentation refers to the ability to remove a region based on the connected criteria. In this segmentation, neighbouring pixels were analysed and joined. Initial seed points were needed in determining which pixels should be added to the region (Bischof, 1994).

Scalar-based segmentation refers to the segmentation process based on the RGB values of the dataset (Oehler et al., 2011). It is depending on the scalar field which is the set of values associated to points that are possible to be represented in colour values.

\subsection{Case Study}

The study focused on the immovable asset of a community hall that is located in Taman Kobena, Johor Bahru. The asset of focus here is the Dewan Muafakat which can be seen in the map of Figure 1.

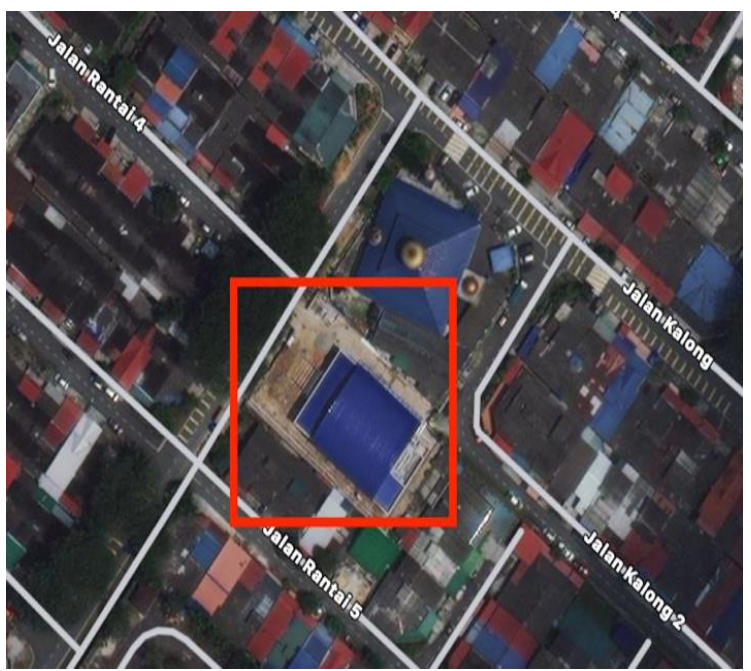

Figure 1: Location of Dewan Muafakat (Source: Google Map)

\subsection{METHODOLOGY}

To perform the segmentation and eventually information assessment of the asset, various approach have been done from the data acquisition, data processing and data presentation. Hardware includes drone and laptop have been used while software such Pix4D, CloudCompare, Microsoft Visual Studios and SketchUp are the useful tools in realising the purpose of this research. The research flow can be visualised in Figure 2.

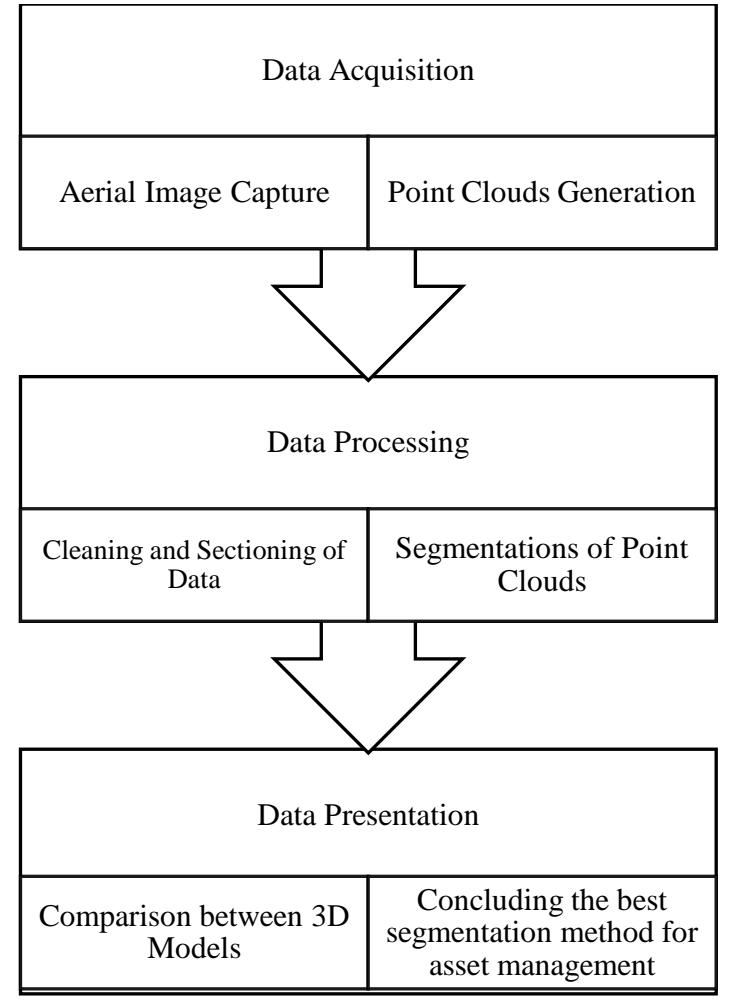

Figure 2: Flow of Research

\subsection{Data Acquisition}

The structure of Dewan Muafakat were surveyed through the means of photogrammetry. Photogrammetry is the method of producing an output based on the real-world objects. The means of aerial survey is used to capture the images of Dewan Muafakat through the use of drone. A total of 60 images that surrounds the features of Dewan Muafakat were captured using drone. In this process, the area of Taman Kobena that encloses the study of Dewan Muafakat undergoes the aerial survey.

From the captured images via airborne survey, point cloud will be generated. Point Clouds refers to the set of points from a scanned object that has 3D features in it. The point cloud can preserve the original condition of the object surface which makes its beneficial for implementing 3D asset management. In this study, the point cloud is generated from the 60 images captured via Pix4D software. The collected aerial images were processed for point cloud generating and analysis. The generated point cloud is exported in LAS format. The detailed process will be discussed in the next section.

\subsection{Data Processing}

Several software were involved in the processing of point clouds. The software involved includes Pix4D, CloudCompare, Microsoft Visual Studio and SketchUp. The software mentioned that on the fundamental of producing point clouds that were generated from the drone's captured imagery of Dewan Muafakat. Initially, Pix4D was the first software that involved as the part of the pre-processing of image. The image undergoes the 
process of registration. Registration is the process where the image is combined to perform a specific model based on the features available in the image. The generating point cloud will be in two parts namely "Initial Processing" and "Point Cloud and Mesh". The "Initial Processing" is where the images are aligned geographically into their position while "Point Cloud and Mesh" is where the generation of point cloud is happened.

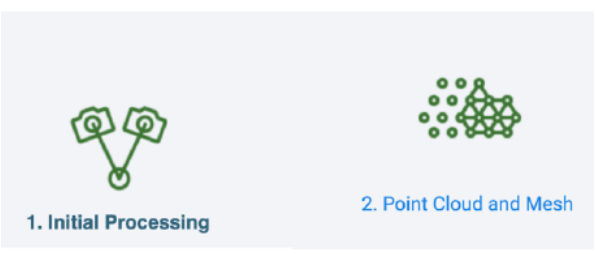

Figure 3: Processing of Point Cloud Phase

The results are obtained through the registration process will be the point clouds. The result will be exported into LAS file which then will be used for other processes later. The generated point clouds will then go through the process of noise filtering to mitigate possible errors occurred. The processed image will be transformed into a dataset of point clouds that are very important for the segmentation processes. Pix 4D is the preferred software due to its efficiency and user-friendly interface that made it easier for users to understand and execute the processing of drone image. The generated point cloud were saved as .pcd file. The results can be seen in Figure 4.

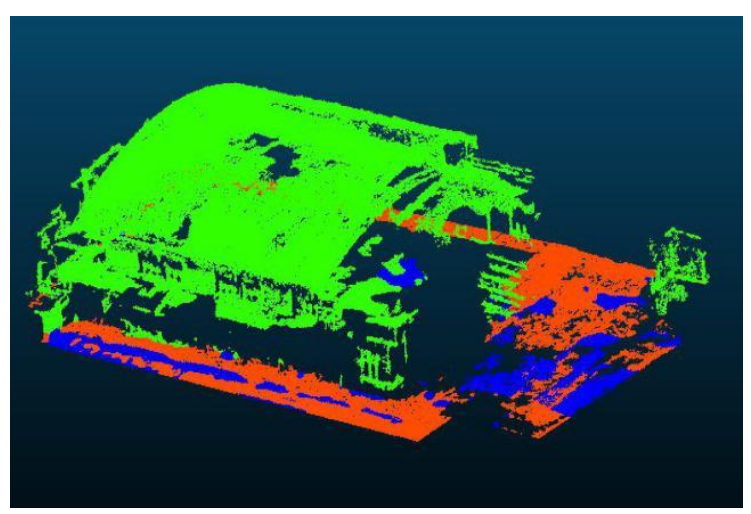

Figure 4: Point Cloud Dataset for Dewan Muafakat

The point clouds will then be transferred into CloudCompare, an open-source software which caters to the processing of point clouds. In here, the extraction of point clouds were made where Dewan Muafakat is the main target for the segmentation processes. The remaining point clouds that cover the rest of the images view were removed. This will then be proceeded to the first method of segmentation, Scalar-based segmentation.

Scalar-based segmentation was performed based on the scalar value that are available on the point clouds. The segmentation processes were made manually by extracting the features that are based on the scalar value. The segmented parts will determine how the software assess the point clouds in determining different features on the building. The result will show a new set of point cloud data. Instead of normal RGB point cloud that represents the real features of Dewan Muafakat, the latter result was shown in scalar-based form. This result makes it easier for further segmentation process in the approach. Figure 5 shows the segmented parts based on the scalar values.

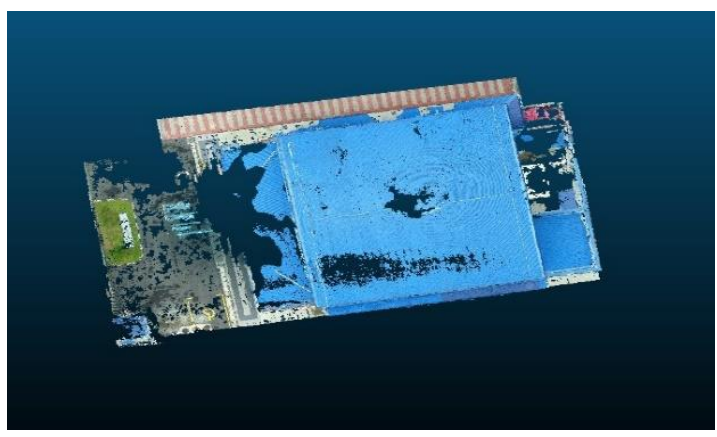

Figure 5: Scalar-Based Segmentation of the asset

The features of the segmented area will be extracted into new data then will be displayed in new window. The extraction was done to separate the features from the scalar values from the whole point cloud dataset of Dewan Muafakat which showcasing different features that will be added as the new dataset. The whole process of scalarbased Segmentation can be simplified via the flowchart. The flowchart of the process can be referred to as Figure 6.

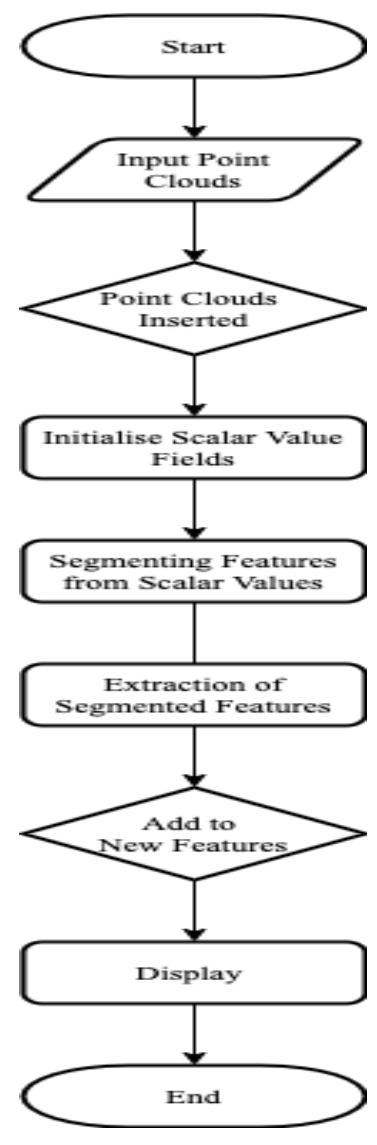

Figure 6: Flowchart of Scalar-Based Segmentation 
Next, region-growing based segmentation. This segmentation uses a coding approach via $\mathrm{C}++$ as the programming language. Microsoft Visual Studio is the platform to develop computer program. Using the source code that is available in Point Cloud Library (PCL), the segmentation process was done through the use of pcd file that has been produced earlier from CloudCompare. .pcd file is used as the PCL source code has its limitation of reading only .pcd file and CloudCompare is capable of generating the file type. The source codes can be viewed in Figure 7.

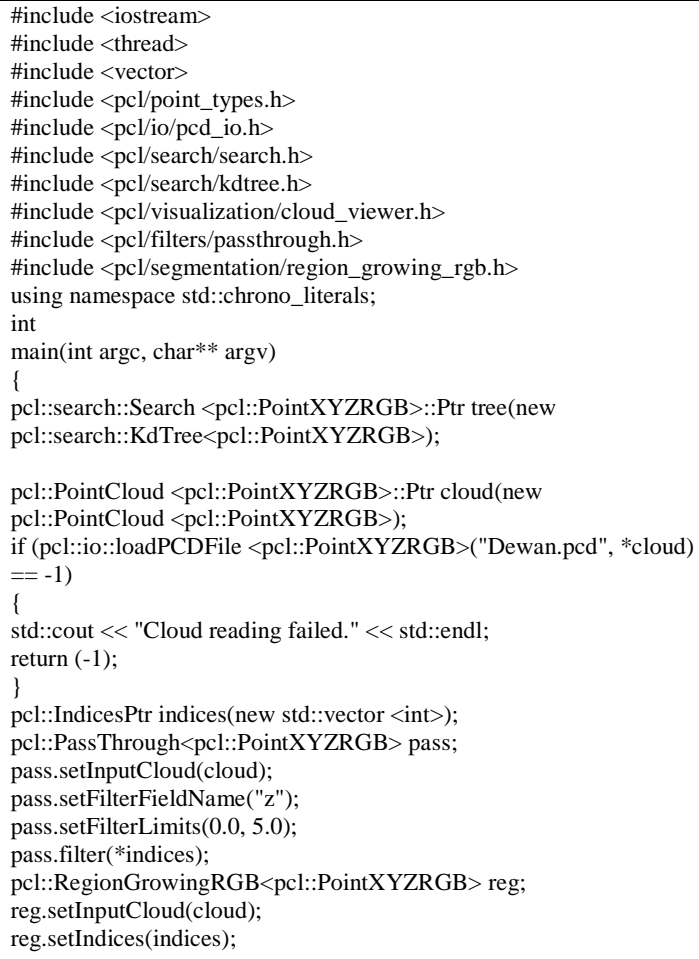

Figure 7: Source codes used

The process of the Region-Growing Segmentation can be explained in a sequential way. The first thing that will be done is to input of the point clouds data. In this case, the data must be in .pcd file in order to be compatible with the source codes. Failure to comply with the requirements will make the process halted. This is the reason why the point clouds dataset was exported in .pcd file in the CloudCompare software. The success in the insertion of point clouds file will trigger the initialisation of region lists. This process involves scanning the point clouds as the preliminary process before segmentation process begins. Region-Growing segmentation is based on the findings of seed points. The next step in the source codes will focus on this. Seed points will be located and the detected object that accumulates in the region will be segmented while the undetected will be ignored. The segmented objects of the point clouds will be then displayed in the CloudViewer. The process can be visualised as shown in Figure 8.

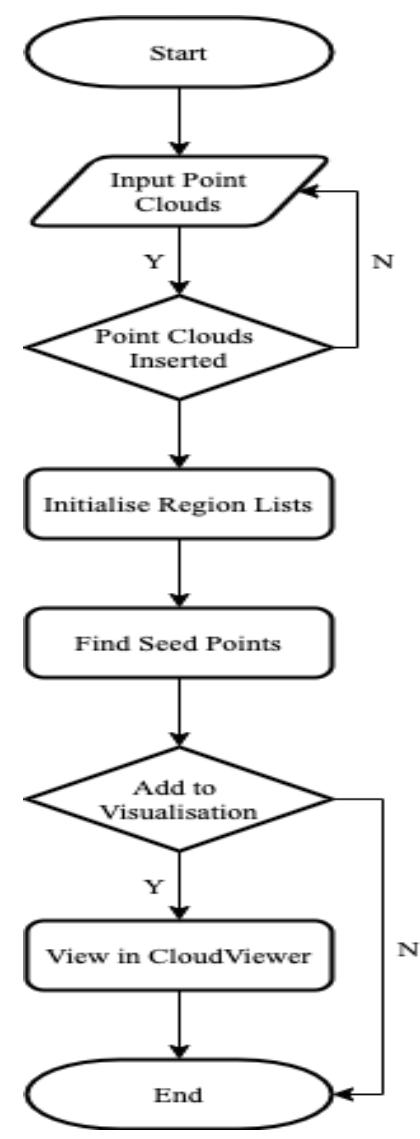

Figure 8: Flowchart of Region-Growing Segmentation

\subsection{Data Presentation}

As both of the segmentation processes were done, a 3D model can be produced. Modelling software was used to model the object based on point clouds. In this instance, SketchUp software is used. SketchUp is a software where multiple tools are available to draw model based on desired motifs. A sufficient skill from the user is required to model the building. However, limitations were found where the point clouds cannot be used in the software due to the inability to import due to the reason of failed interoperability from CloudCompare to SketchUp. Normal modelling approach was done based on the assumption of the point clouds model to create a 3D model from SketchUp.

\subsection{RESULTS AND DISCUSSION}

The increasing efforts in developing smart city concepts are often coupled with three-dimensional (3D) modelling envisioned design (Buyukdemircioglu and Kocaman, 2020). Moreover, the development of 3D modelling and visualization can be associated to the development of smart city (Azri et al., 2016). Thus, the most benefit of 3D 
city models is their ability to simplify visualization, mapping and urban planning (Santos, 2020).

In this research, the point clouds of the case study Dewan Muafakat were collected via drone and pre-processed through the software Pix4D. Through Pix4D, point clouds were generated. CloudCompare software is then used to further sectioned the point clouds and focused on the target area for segmentation processes. From here, scalarbased segmentation was done through the software. Moving on to the next segmentation, region-growing based segmentation was done through coding of $\mathrm{C}++$ through Microsoft Visual Studios. The model of Dewan Muafakat was constructed through SketchUp. The assessment of the segmentation methods was carried out.

\subsection{Scalar-Based Segmentation}

This method focused on the manual segmentation process. The segmentation was done by manually extracting the data based on the scalar filter that can be generated upon the point clouds dataset using the CloudCompare software. The segmentation was based on the scalar filter readily available in the software and filtration was made to the point cloud dataset. The scalar index defined the features of the dataset. From the process, a total of three major features were segmented which include building, ground and concrete ground. The point clouds were extracted into scalar form and also converted in RGB form where the distinct features can be seen from the result. From the result, a 3D model was constructed via Sketchup software which displaying the features of the segmented point clouds. Table 1 shows the results obtained from Scalar-based Segmentation for a clear visualization.

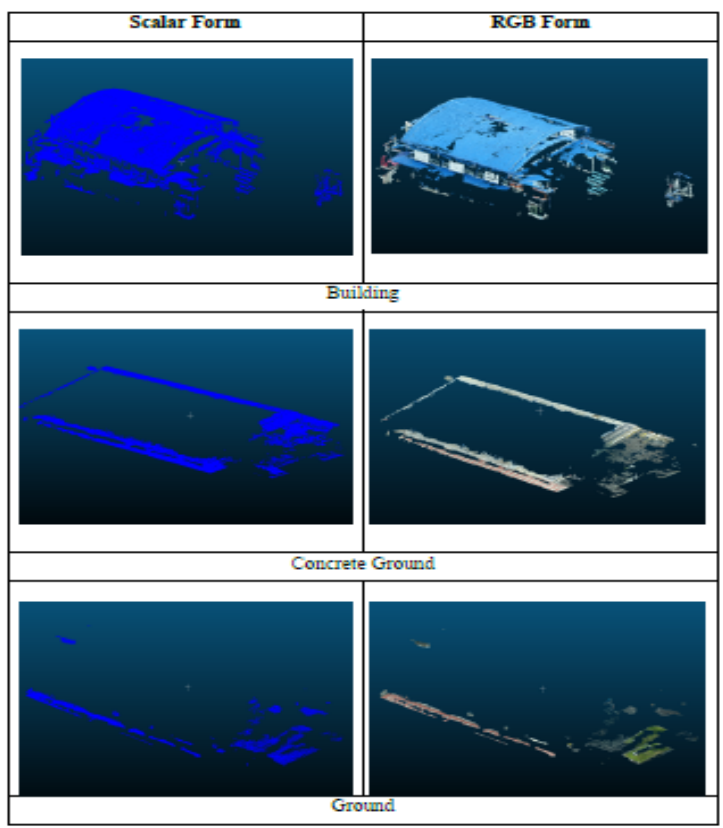

Table 1: Scalar-Based Segmentation results

\subsection{Region-Growing Segmentation}

This method focused on the automatic segmentation process. The segmentation was done from the coding process which the source code was used from the Point Cloud Library (PCL). The source code was then used in the Microsoft Visual Studios as a $\mathrm{C}++$ programming language. This process involved identifying the seed points that will affect the segmentation process. The result was obtained in a special CloudViewer. The result is shown in Figure 9.

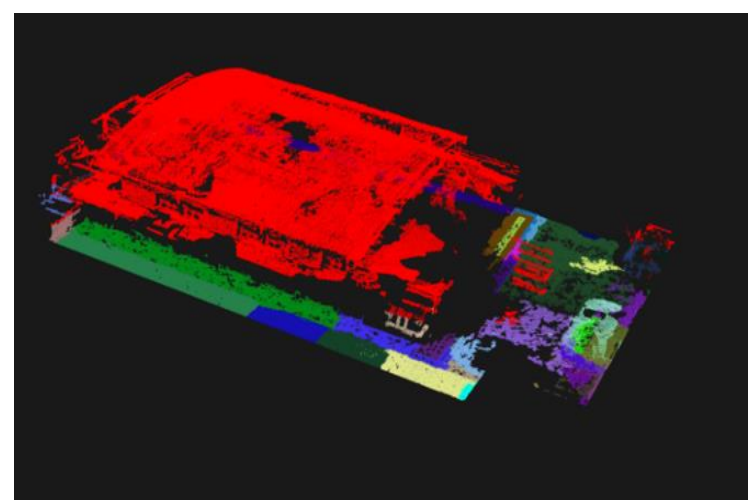

Figure 9: Region-Growing Segmentation result

\subsection{D Modelling and Comparison}

Based on the segmentation processes that were being done, 3D modelling is executed on these two methods where the results will be compared and assessed. The results can be viewed in the following Table 2 .

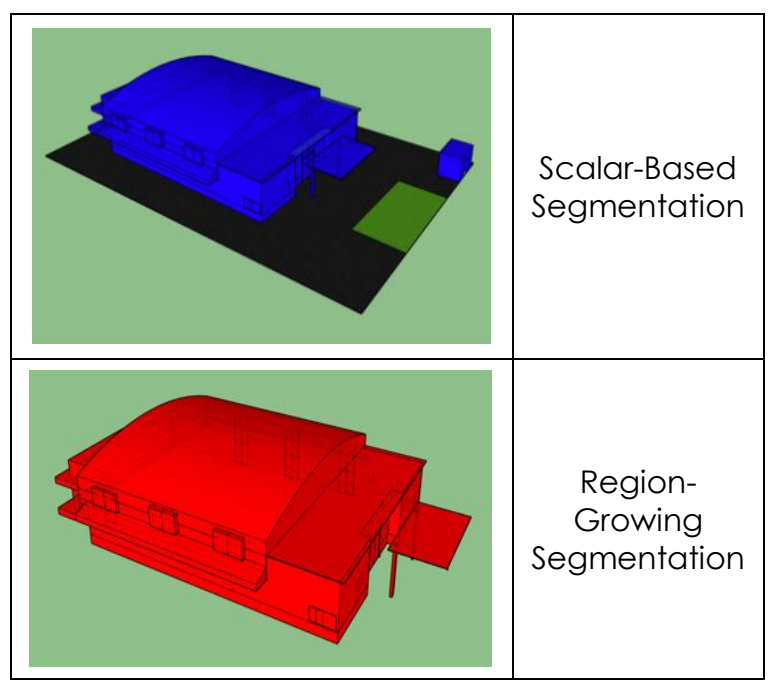

Table 2: 3D Model of Segmented Results

From here, it can be seen that the stark difference between results. The Scalar-Based segmentation provided a much clearer representation to the real features of the asset itself. Three main features were able to be extracted and developed into 3D model. However, the same cannot be said for Region-Growing Segmentation where only the building features were able to be modelled due to the noise generated by the processes. Hence, only the building feature can be modelled as this posed a disadvantage for the asset management. The Scalar-Based Segmentation allows each of the features to be extracted and this is useful for further analysis while Region-Growing 
Segmentation can only be viewed in the window without the capability of extraction. The following Table 3 shows the comparison between the results of the whole process.

\begin{tabular}{|c|c|c|}
\hline Method & Scalar-Based & Region-Growing \\
\hline $\begin{array}{c}\text { Selection } \\
\text { Parts }\end{array}$ & Manual & Automatic \\
\hline $\begin{array}{c}\text { Object } \\
\text { Detected }\end{array}$ & 3 & $\begin{array}{c}1 \\
\text { (Clear } \\
\text { Interpretation) }\end{array}$ \\
\hline Time Taken & 10 Minutes & $\begin{array}{c}15 \\
\text { (Due to Noise) }\end{array}$ \\
\hline Pro(s) & $\begin{array}{c}\text { - Correct } \\
\text { Selection } \\
\text { Elements } \\
\text { - Enabled } \\
\text { Extraction }\end{array}$ & $\begin{array}{l}\text { - Fast and } \\
\text { easy } \\
\text { approach } \\
\text { - No pre- } \\
\text { selection } \\
\text { needed }\end{array}$ \\
\hline Con(s) & $\begin{array}{l}\text { - Further data } \\
\text { cleaning } \\
\text { needed } \\
\text { - Careful } \\
\text { selection } \\
\text { needed }\end{array}$ & $\begin{array}{c}\text { - Inability to be } \\
\text { extracted } \\
\text { - Very sensitive } \\
\text { to noise } \\
\text { - Not suitable } \\
\text { for large data }\end{array}$ \\
\hline
\end{tabular}

Table 3: Comparison between methods

Based on the Table 3, the comparison between Scalar based method and Region Growing Segmentation have stark differences. Scalar-Based Segmentation provided a longer time approximately 10 minutes to be taken for process, this includes the sectioning, cleaning and registering the scalar field values. The process will then divide the features into three parts where the extraction process was done. This is contrasting to the RegionGrowing method where the process only took three minutes. This is largely due to the automatic selection posed by the method which makes it very easy to use. There are more objects detection were found for RegionGrowing method. However, it does not show the accurate representation of the real features due to noise occurs. Meanwhile, using scalar-based method shows the accurate representation of features. From the table, it can be concluded that there are many pros and cons between the two methods. From the Scalar-based Segmentation, the method able to make correct elements selection and enable the element extraction. However, this method needs further data cleaning and a careful selection has to be conducted during the element extraction. For RegionGrowing Segmentation, the method provided are fast and easy to be used and there is no pre-selection has to be conducted during extraction. But, the method also has constraint where it has the inability to be extracted, highly sensitive to noise and not suitable for large data. Therefore, both of the methods have their own pros and cons, hence the most suitable method must be chosen carefully based on our criteria, data specification and the output needed.
With the growing globalization and urbanization, development of smart cities has turned out to be a necessity (Chaturvedi, 2019). Management of assets that are integrated with $3 \mathrm{D}$ modelling and visualization is a part of the smart city development. The asset management in three-dimensional approach consists of data collections, management, analysis, modelling and visualising 3D city models according to smart city standard. From the analysis, it can be concluded that by using Scalar-Based segmentation is a superior alternative for the use of asset management. It has been proven that by using this method shows a better accuracy in terms of visual appearances that can be further analysed for other works.

The objective of managing the point clouds data for asset management has been achieved where the input and output of the data were finalised by using specific hardware and software. The identification of the best segmentation method was known through the comparison between Scalar-Based and Region-Growing segmentation method. It is apparent to see the comparison through the discussion which states that the first method is superior. The results were finally designed in a 3D model where the visual comparison were made there for a better understanding of the nature of the asset. Such feat is important for immovable assets to undergo the process of management in an easier way through the implementation of 3D asset management. Segmentation really helps in understanding the features that is possibly hard to identify by normal observations.

This paper presented a review on the segmentation methods using two different approaches, scalar-based segmentation and region-based segmentation. The difference between these two methods were assessed and it can be seen the benefits posed by both methods. Some can pose disadvantages over others. Careful selection of segmentation methods should be performed in order to reduce the problems while handling the asset management. This research is still an open topic and more experimental tests should be carried out. In the future, it is feasible that the study and approach of segmentation should be further improved so that point clouds data can be handled much more effectively and efficiently. This research is focused on the management of the immovable assets. It is recommended in the future that more researches can be done for moveable assets where the objects vary and more detailed.

\section{ACKNOWLEDGEMENTS}

This research was partially funded by UTM Research University Grant, Vot Q.J130000.3552.06G41 and Vot R.J130000.7652.4C332

\section{REFERENCES}

Ajith Kular Parlikad, M. A. J. 2016. Challenges in Infrastructure Asset Management. Ifac-Papersonline, Volume 49, 185-190.

Azri, S., Anton, F., Ujang, U., Mioc, D., Rahman, A.A., 2015. Crisp Clustering Algorithm for 3D Geospatial Vector Data Quantization, Lecture Notes in 
Geoinformation and Cartography. Springer Verlag, pp. 71-85.

Azri, S., Ujang, U., Abdul Rahman, A., 2018. Dendrogram Clustering for 3D Data Analytics in Smart City. International Archives of Photogrammetry, Remote Sensing and Spatial Informtion Science. XLII-4/W9, 247253

Azri, S., Ujang, U., Anton, F., Mioc, D., Rahman, A.A., 2014. Spatial Access Method for Urban Geospatial Database Management: An Efficient Approach of 3D Vector Data Clustering Technique, 9th International Conference on Digital Information Management (ICDIM). IEEE, Bangkok, Thailand.

Azri, S., Ujang, U., Castro, F. A., Rahman, A. A. \& Mioc, D. 2016. Classified and Clustered Data Constellation: An Efficient Approach of 3d Urban Data Management. ISPRS Journal of Photogrammetry and Remote Sensing, 113, 3042.

Bastian Oehlerm Joerg Stueckler, J. W., Dirk Schulz, Sven Behnke 2011. Efficient Multi-Resolution Plane Segmentation of 3d Point Clouds. Springer-Verlag Berlin Heidelberg, 145-156.

Bischof, R. A. A. L. 1994. Seeded Region Growing. IEEE Transactions On Pattern Analysis and Machine Intelligence, Vol. 16.

Brous, P., Herder, P. \& Janssen, M. 2015. Towards Modelling Data Infrastructures in The Asset Management Domain. Procedia Computer Science, 61, 274-280.

Buyukdemircioglu, M. \& Kocaman, S. 2020. Reconstruction and Efficient Visualization of Heterogeneous 3D City Models. Remote Sensing, 12, 2128.

Chaturvedi, A. 2019. Tech Integration, Multilevel Collaboration and Holistic 3d Modelling Pivotal for Smart City Development [Online]. Geospatial World. Available:

Https://Www.Geospatialworld.Net/Blogs/MultilevelIntegration-3d-Modelling-Smart-City-Development/ [Accessed 23/7/2020].

El-Gamily, H. I. \& Al-Rasheed, K. 2015. Deploying an Interactive GIS System for Facility and Asset Management: Case Study-Ministry of Education, Kuwait. Journal of Geographic Information System, 07, 191-201.

Esri 2014. 3D Urban Mapping: From Pretty Pictures to 3D GIS.

Fabrizio I. Apollonio, M. G., Benedetto Benedetti 2012. 3d Reality-Based Artefact Models for The Management of Archaeological Sites Using 3D GIS: A Framework Starting from The Case Study of the Pompeii Archaeological Area. Journal of Archaeological Science, Volume 39, 1271-1287.

Grilli, E., Menna, F. \& Remondino, F. 2017. A Review Of
Point Clouds Segmentation and Classification Algorithms. ISPRS - International Archives of the Photogrammetry, Remote Sensing and Spatial Information Sciences, Xlii-2/W3, 339-344.

Haberly, D., Macdonald-Korth, D., Urban, M. \& Wójcik, D. 2019. Asset Management as A Digital Platform Industry: A Global Financial Network Perspective. Geoforum, 106, 167-181.

Harborresearch. 2020. Smart Cities \& Infrastructure [Online]. Habor Research Inc. Available: Https://Harborresearch.Com/Smart-Cities/ [Accessed 23/7/2020].

Innovation, C. C. 2007. Adopting BIM for Facilities Management: Solutions for Managing the Sydney Opera House, Brisbane, Australia, Cooperative Research Centre for Construction Innovation.

Isabella Toschi, E. N., Fabio Remondino 2017. Geomatics Makes Smart Cities a Reality. GIM International.

Keling, N., Mohamad Yusoff, I., Lateh, H., Ujang, U., 2017. Highly Efficient Computer Oriented Octree Data Structure and Neighbours Search in 3D GIS, in: AbdulRahman, A. (Ed.), Advances in 3D Geoinformation. Springer International Publishing, Cham, pp. 285-303.

Koller, D., Frischer, B. \& Humphreys, G. 2009. Research Challenges for Digital Archives of 3D Cultural Heritage Models. Journal On Computing and Cultural Heritage, 2, $1-17$.

Lemmens, M. 2018. Point Cloud and Smart Cities. GIM International.

Liu, X., Qiao, Y., Chen, X., Miao, J. \& Duan, L. 2016. Color Image Segmentation Based On Modified Kuramoto Model. Procedia Computer Science, 88, 245-258.

Makkonen, S. 2016. Semantic 3D Modelling for Infrastructure Asset Management. Aalto University.

Mohd, Z.H., Ujang, U., 2016. Integrating Multiple Criteria Evaluation and GIS in Ecotourism: A Review. International Archives of Photogrammetry, Remote Sensing and Spatial Informtion Science. XLII-4/W1, 351354.

Murtiyoso, A., Pierre, G. 2019. Point Cloud Segmentation And Semanticannotation Aided By Gis Data Forheritage Complexes. 8th International Work-shop 3D-ARCH " $3 D$ Virtual Reconstruction and Visualization of Complex Architecture", XLII-2/W9, 523-528.

Nguyen, A., Bac, L. 2013. 3D Point Cloud Segmentation: A Survey. 6th Ieee Conference On Robotics, Automation And Mechanics (Ram), 225-230.

Oehler, B., Stueckler, J., Welle, J., Schulz, D. \& Behnke, S. 2011. Efficient Multi-Resolution Plane Segmentation of $3 \mathrm{~d}$ Point Clouds. Intelligent Robotics and Applications, 7102, 145-156. 
R.V. Hari Ginardi, W. G., Septiawan Resetya Wardana 2017. WebGIS for Asset Management of Land and Building of Madiun City Government. F4th Information Systems International Conference 2017, 437-443.

Rouse, M. 2020. Smart City [Online]. Internet of Things Agenda. Available: Https://Internetofthingsagenda.Techtarget.Com/Definitio n/Smart-City [Accessed 22/7/2020].

Santos, B. 2020. 5 Ways 3D City Models Plan a Better Tomorrow for Urban Communities [Online]. Microdesk. Available: Https://Www.Microdesk.Com/Articles/5Ways-3d-City-Models-Plan-A-Better-Tomorrow-ForUrban-Communities/ [Accessed 23/7/2020].

Shiota, A., Fuchino, G., Koyamatsu, Y., Kakumoto, Y., Tanoue, K., Qudaih, Y. \& Mitani, Y. 2016. Guide Construction of an Efficient Inspection, Maintenance and Asset Management of Photovoltaic Power Generation System Using GIS. Energy Procedia, 100, 69-77.

Stephens, D., Smith, A., Redfern, T., Talbot, A., Lessnoff, A. \& Dempsey, K. 2020. Using Three Dimensional Convolutional Neural Networks for Denoising Echosounder Point Cloud Data. Applied Computing and Geosciences, 5, 100016.

Salleh, S., Ujang, U., 2018. Topological information extraction from buildings in CityGML. IOP Conference Series: Earth and Environmental Science 169, 012088.

Thales. 2019. Secure, Sustainable Smart Cities and The Lot [Online]. Thales Group. Available: Https://Www.Thalesgroup.Com/En/Markets/DigitalIdentity-And-Security/Iot/Inspired/Smart-Cities [Accessed 22/7/2020].

Toschi, I., Nocerino, E., Remondino, F., Revolti, A., Soria, G. \& Piffer, S. 2017. Geospatial Data Processing for 3D City Model Generation, Management and Visualization. ISPRS - International Archives of the Photogrammetry, Remote Sensing and Spatial Information Sciences, Xlii-1/W1, 527-534.

Volkov, A., Danilina, N., Slepnev, M., Chebotarev, S., Pustovgar, A. \& Adamtsevich, A. 2018. Smart City: Automatic Reconstruction of 3D Building Models to Support Urban Development and Planning. Matec Web of Conferences, 251, 03047.

Yang, Y., Gao, X. \& Yang, G. 2011. Study The Method of Vehicle License Locating Based On Color Segmentation. Procedia Engineering, 15, 1324-1329.

Yusoff, I.M., Ujang, U., Rahman, A.A., Katimon, A., Ismail, W.R., 2011. Influence of georeference for saturated excess overland flow modelling using 3D volumetric soft geo-objects. Computers \& Geosciences $37,598-609$. 